Check for updates

Cite this: RSC Adv., 2018, 8, 32241

\title{
Periodic DFT study of structural transformations of cocrystal NTO/TZTN under high pressure $\uparrow$
}

\author{
Guo-zheng Zhao (D) * and Dong-fang Yang
}

Density functional theory (DFT) periodic calculations were performed to study the geometrical and electronic structures of energetic cocrystal NTO/TZTN under pressures ranging from 0 to $80 \mathrm{GPa}$. The optimized crystal structure by the GGA/PW91 (Perdew-Wang-91) and dispersion corrections corresponds well with the experimental values under ambient pressure. With the pressure increasing, the lattice constants, unit cell volumes, interatomic distances, $\mathrm{H}$-bond energies, atomic charges, and bond populations of cocrystal NTO/ TZTN change gradually. At pressures of 4, 8, and $23 \mathrm{GPa}$, three structural transformations occurred, shown by the results. The cyclization plays an important role in stabilizing the systems. The increasing pressure contributes to the increase of interaction force gradually. At $4 \mathrm{GPa}$, a new hydrogen bond $\mathrm{O} 3 \cdots \mathrm{H} 5$ is formed. At $8 \mathrm{GPa}$, the formation of eight membered rings is because of the existence of a covalent bond $\mathrm{O} 1-\mathrm{H} 3$ between two NTO molecules. In addition, a covalent interaction is formed between N2 and H4 atoms with the biggest $\mathrm{H}$-bond energy compared to the others. As the pressure reaches $23 \mathrm{GPa}$, another new hydrogen bond forms between N8 and H5 atoms, which contributes to the formation of a five membered ring between NTO and TZTN. The electrons can move freely according to the results of the density of states between the valence and conduction bands when the pressure is high. This work will provide useful information in understanding the high-pressure effect on the structural transformation.

Received 12th June 2018

Accepted 6th September 2018

DOI: $10.1039 / \mathrm{c} 8 \mathrm{ra05029e}$

rsc.li/rsc-advances incorporation of TNT with the same molar ratio. ${ }^{18}$ The physicochemical properties of HNIW was adapted by Millar et al. through the formation of cocrystals with several solvents. ${ }^{19}$ Bolton et al. explored a cocrystal HNIW/HMX with high explosive power and good mechanical sensitivity in $2: 1$ molar ratio. ${ }^{20}$ Due to completely different packing model of energetic compounds, cocrystallization offers an alteration of properties including density, impact sensitivity, and explosive performance, which help to obtain explosives with better comprehensive performance. This provides an opportunity to modify the physico-chemical properties of existing explosive and prepare superior cocrystal with better integrated properties at the molecular level.

In 1905, a nitrogen-rich explosive, named 3-nitro-1,2,4triazol-5-one (NTO), was synthesized for the first time, with sensitivity comparable to that of 1,3,5-triamino-2,4,6-trinitro benzene (TATB), while the performance are as same as that of RDX. However, it is a dibasic acid explosive, which limits its further applications. ${ }^{21-23}$ For the sake of decreasing the acidity of NTO, Zhang et al. cocrystallized NTO with 5,6,7,8-tetrahydrotetrazolo[1,5- $b][1,2,4]$-triazine (TZTN), which demonstrated that the cocrystal contributed to the enhancement of thermal stability and became less sensitive to impact, compared with the TZTN. ${ }^{24}$ Chen et al. conducted a research about the cocrystal NTO/TZTN with the application of GGA/PBE method and analyzed its structural, mechanical, and thermodynamic properties and impact sensitivity. ${ }^{25}$ As a complex chemical behavior, it is challengeable to investigate the microscopic properties of
Key Laboratory of Magnetic Molecules \& Magnetic Information Materials Ministry of Education, The School of Chemical and Material Science, Shanxi Normal University, Linfen 041004, China. E-mail: zhaoguozheng99@126.com

$\dagger$ Electronic supplementary information (ESI) available. See DOI: 10.1039/c8ra05029e 
energetic crystals. At the same time, the research of high pressure behavior of energetic crystals plays a significant role in experimental measurements. Theoretical calculation is an effective way to model the properties of energetic crystals in physical and chemical fields in comparison to the experimental work. ${ }^{26-29}$ Deep research on the behavior of cocrystal NTO/TZTN under high pressures is of vital importance for the understanding of its chemical reactivity, detonation process, structural stabilities, and sensitivity. However, the cocrystal experiments mainly focus on the preparation, characterization, and performance test as well as the evaluation of impact sensitivities. ${ }^{30-33}$ Fewer research focused on the relationship between structure and properties under high pressures. According to the application of density functional theory method with pseudopotentials and a planewave of basis set, the investigation of the structures and properties of energetic crystals has been successfully performed under hydrostatic compression. ${ }^{34}$ Sorescu et al. predicted the crystallographic lattice parameters of representative molecular explosive crystals by DFT-D as implemented in a pseudopotential plane-wave code under the ambient and high pressure conditions, ${ }^{35}$ which shown that the cell parameters were obtained with an accuracy less $2 \%$ in comparison to the experimental values at ambient pressures, and also can be predicted accurately at high pressures. Hu et al. calculated the elastic stability of $\beta$-Ti at various pressures by the first-principles plane-wave pseudopotential method..$^{36}$ It is found that, the pseudopotential results are the same as and ideally close to all-electron full-potential augmented plane-wave calculations under low and high pressure, respectively. Currently, the first principle periodic calculations were performed to study the crystal, molecular, and electronic structures of cocrystal NTO/TZTN. The high pressure behavior of cocrystal NTO/TZTN were investigated in the range of 0-80 GPa.

\section{Computational methods}

The first-principle calculations were performed by the application of DFT method with the combination of Vanderbilt-type ultrasoft pseudopotential ${ }^{35,36}$ and a plane-wave expansion of the wave functions ${ }^{37}$ implemented in the CASTEP ${ }^{38}$ module of Materials Studio 6.0.39 The initial crystal was taken from Zhang et al. (CCDC 1042895) ${ }^{24}$ and designed to the following computations. The cocrystal NTO/TZTN crystallizes in monoclinic space group $P 22_{1} / c$ with $a=27.104 \AA, b=10.093 \AA$, and $c=$ 14.741 A. Fig. 1 illustrates the crystal structures of NTO, TZTN and cocrystal NTO/TZTN. Under the hydrostatic pressures of $0-$ $80 \mathrm{GPa}$, the research has been conducted to investigate the pressure effect on the geometrical and electronic structures of cocrystal NTO/TZTN.

Single point energies calculations were conducted at the B97$\mathrm{D} / 6-311++\mathrm{G}^{* *}$ level of DFT with Gaussian 09 (ref. 40) suite. The Quantum theory of atoms in molecules (QTAIM) analyses were performed by employing Multiwfn ${ }^{41}$ with the input files (.wfn) generated from Gaussian. The electron density $\left(\rho_{\mathrm{CP}}\right)$ and its Laplacian $\left(\nabla^{2} \rho\right)$ at the critical point, the electron potential energy density $\left(V_{\mathrm{BCP}}\right)$, the total electron energy density $\left(H_{\mathrm{BCP}}\right)$, and the Lagrangian kinetic energy $\left(G_{\mathrm{BCP}}\right)$ were obtained based on the characteristics of the bond critical point (BCP). The relations between the topology parameters are shown in eqn (1):

$$
\frac{1}{4} \nabla^{2} \rho=2 G_{\mathrm{BCP}}+V_{\mathrm{BCP}}, \quad H_{\mathrm{BCP}}=G_{\mathrm{BCP}}+V_{\mathrm{BCP}}
$$

Espinosa et al. introduced eqn (2) which was used for obtaining of the relationship between H-bond energy $\left(E_{\mathrm{H}}\right)$ and $V_{\mathrm{BCP}}:^{42}$

$$
E_{\mathrm{H}}=\frac{1}{2} V_{\mathrm{BCP}}
$$

\section{Results and discussion}

Seven different functionals, local density approximation (LDA) and generalized gradient approximation (GGA), as a test, were applied to the computation of cocrystal NTO/TZTN. To benchmark the performance of theoretical approach, LDA/CA-PZ, GGA/PBE (Perdew-Burke-Ernzerhof), ${ }^{43}$ GGA/PW91(Perdew-

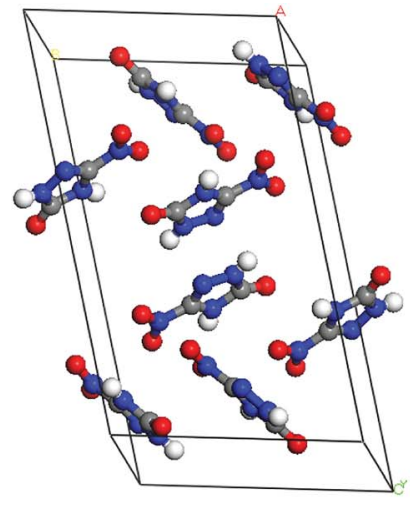

NTO

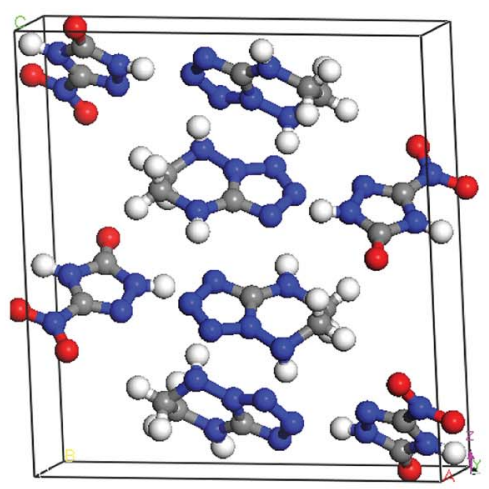

NTO/TZTN

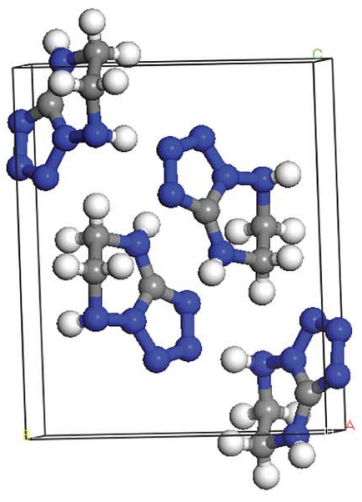

TZTN

Fig. 1 Crystal structures of NTO, TZTN and NTO/TZTN cocrystal. 
Table 1 Comparison between relaxed lattice parameters of cocrystal NTO/TZTN and experimental data at ambient pressure ${ }^{a}$

\begin{tabular}{|c|c|c|c|c|c|}
\hline Method & $a(\AA)$ & $b(\AA)$ & $c(\AA)$ & $\beta$ (deg) & Vol. $\left(\AA^{3}\right)$ \\
\hline LDA/CA-PZ & $13.107(-3.14)$ & $5.015(-2.32)$ & $14.741(0.10)$ & $95.81(3.87)$ & $963.9(-5.72)$ \\
\hline LDA/CA-PZ-OBS & $13.146(-2.85)$ & $4.635(-9.72)$ & $13.509(-8.27)$ & $88.63(-3.91)$ & $822.8(-19.52)$ \\
\hline GGA/PBE-TS & $13.611(0.58)$ & $5.158(0.47)$ & $15.118(2.65)$ & $91.83(-0.44)$ & $1060.9(3.77)$ \\
\hline GGA/PBE-G06 & $13.405(-0.94)$ & $5.096(-0.74)$ & $15.289(3.82)$ & $93.03(0.86)$ & $1043.0(2.01)$ \\
\hline GGA/PW91 & $13.539(0.05)$ & $5.783(12.64)$ & $17.219(16.92)$ & $93.86(1.76)$ & $1345.1(31.56)$ \\
\hline
\end{tabular}

${ }^{a}$ The values in parentheses correspond to the percentage differences relative to the experimental data.

Wang-91 $)^{44}$ and dispersion corrections were selected to fully relax the cocrystal NTO/TZTN without any constraint at ambient pressure. The experimental and relaxed cell parameters of cocrystal NTO/TZTN are listed by Table 1 . The relative errors of the calculated values to the experimental ones indicate that the calculated values of GGA/PW91-OBS is much closer to the experimental ones than the others. The GGA/PW91-OBS method is more suitable for studying cocrystal NTO/TZTN, which is different from the previous studies in term of energetic crystals ${ }^{45,46}$ show that more reliable lattice parameters could be produced by the LDA functional than the GGA. Therefore, GGA/PW91-OBS method has been employed in the present study.

\subsection{Crystal structure}

In general, intermolecular interactions, with the feature of weakness, are easy to compress in comparison with chemical bonds. The reduction of structural spaces in the crystal is the first structural response under an applied pressure. Because the flexible conformation of molecule, the changes of molecular conformation or the transformation of structure lead to the transitions of phase and the formation of denser packed materials under higher pressure. The crystals NTO and NTO/ TZTN exist in space groups of $P 2_{1} / c$, and space group of $P 2_{1} / n$ for TZTN crystal. The molecules per unit cell are irreducible by the number of 4,4 , and 8 ( 4 for NTO and 4 for TZTN) in NTO, TZTN, and cocrystal NTO/TZTN, respectively. Fig. 2 described the relaxed lattice constants, compression rates, and unit cell volumes of cocrystal NTO/TZTN in the pressure range of $0-$ $80 \mathrm{GPa}$. At $0 \mathrm{GPa}$, the experimental values are agreed with the calculated lattice constants. With the pressure increasing, the lattice constants $(a, b, c)$ and unit cell volume $(V)$ decrease gradually. $c$ is easier to compress than $a$ and $b$ from 0 to $80 \mathrm{GPa}$, due to the enough external pressure, which is able to overcome
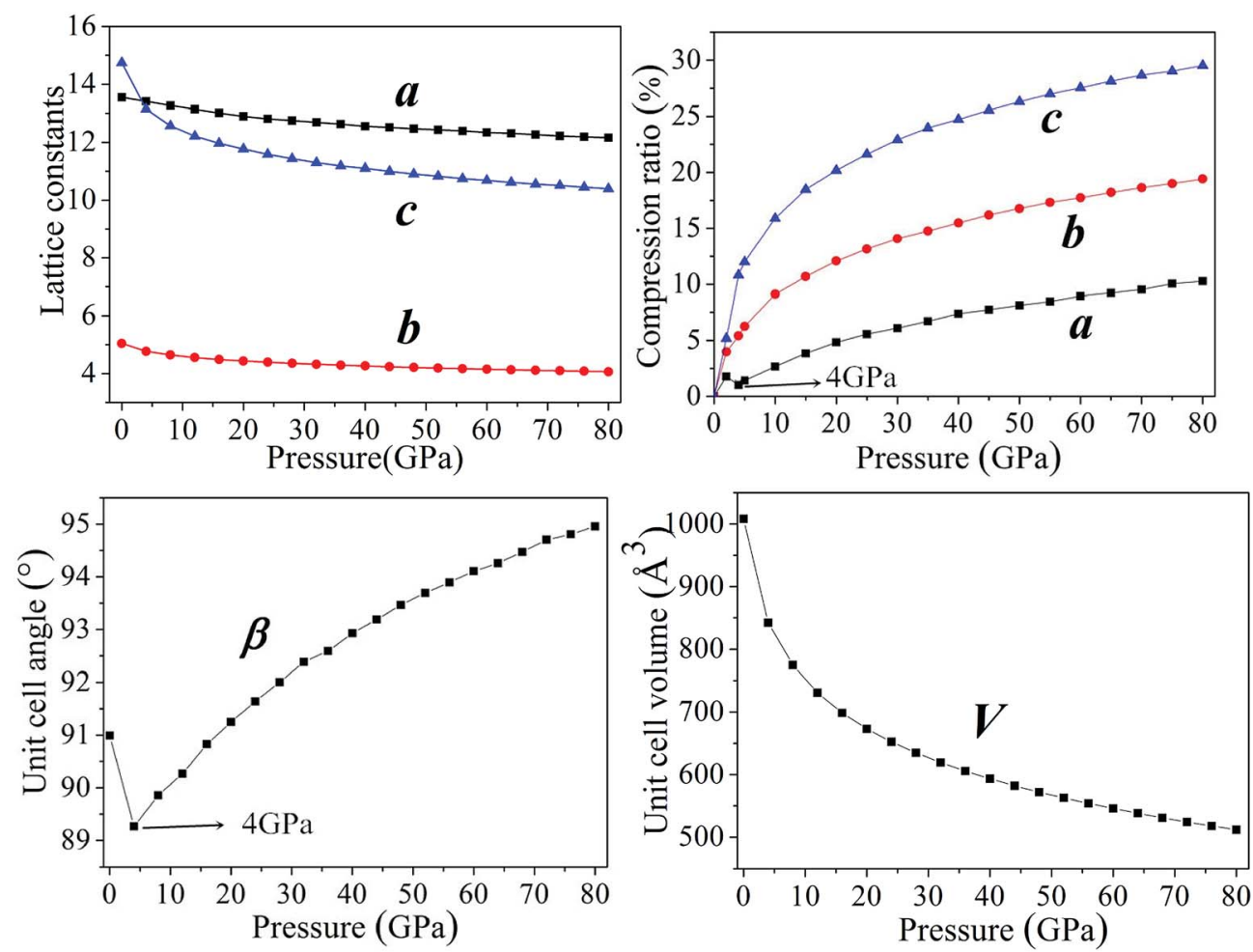

Fig. 2 The description of lattice constants and unit cell volume of cocrystal NTO/TZTN under various pressures. 
the intermolecular repulsion along the crystallographic directions and leads the crystal structure shrinkable, which is in line with the experimental result that the cocrystal NTO/TZTN becomes more and more compact. ${ }^{24}$ Resultantly, the unit cell volume shrinks slowly and accordingly the rise of cocrystal density and total energy is evident with the increase of pressure. ${ }^{47-49}$ Intermolecular interaction becomes more and more strong as the molecules get closer with each other. Comparing to the crystallographic density $\left(1.665 \mathrm{~g} \mathrm{~cm}^{-3}\right)$, cocrystal density increased by around $99.76 \%$ and reached the biggest value under $80 \mathrm{GPa}^{24}$ Knowingly, with the increasing of crystal density, the detonation velocity increases as well resulted from $\mathrm{K}-\mathrm{J}$ empirical equations, ${ }^{47}$ which are also shown that detonation pressure varies with the square of crystal density. The detonation velocity and pressure are improved remarkably when the cocrystal density increases to $2.022 \mathrm{~g} \mathrm{~cm}^{-3}$ at $4 \mathrm{GPa}$.

According to Fig. 2, the ratio of total compression reaches $49.22 \%$ under the pressure range 0-80 GPa. The largest compression of unit cell takes place in the pressure region below $20 \mathrm{GPa}$. The compression ratio $a$ at $4 \mathrm{GPa}$ is anomalously smaller than that at $3 \mathrm{GPa}$, and increases abnormally again at $5 \mathrm{GPa}$. In the pressure range of $0-80 \mathrm{GPa}$, the compression ratios along three directions are not tantamount. The one in $c$ direction is significantly greater than those in $a$ - and $b$-directions in a sequence of $c>b>a$. At $30 \mathrm{GPa}$, the total compression ratios along three directions of $a, b$, and $c$ are $6.09 \%, 14.07 \%$, and $22.90 \%$, respectively, which shows that cocrystal compressibility is anisotropic and the structure is much stiffer in $a$ direction in comparison with those in $b$ and $c$ directions. Moreover, it is noticeable that the unit cell angle $\beta$ decrease gradually under the pressure range 0-4 GPa. Comparing with that at $4 \mathrm{GPa}, \beta$ is remarkably larger at $5 \mathrm{GPa}$, which matches well with the change of compression ratio, meanwhile introducing the suggestion that the large changes have taken place in crystalline form under the pressure of $4 \mathrm{GPa}$. The perspective view of the cocrystal NTO/TZTN with pressures is also demonstrated in Fig. 3. With the structural transformations of cocrystal NTO/TZTN have firstly taken place under the pressure of $4 \mathrm{GPa}$, the large changes in the structures of cocrystal followed.

\subsection{Molecular structure}

3.2.1 Bond length and interatomic distance analysis. In this work, the cyclization was found in cocrystal NTO/TZTN

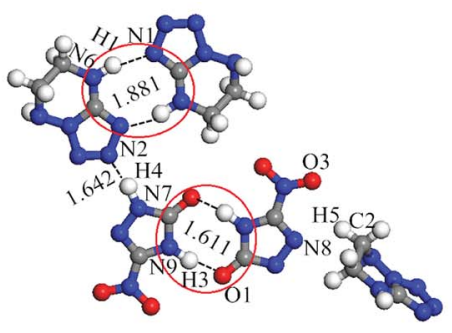

$0 \mathrm{GPa}$

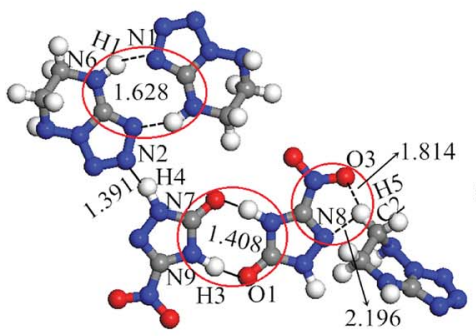

$23 \mathrm{GPa}$

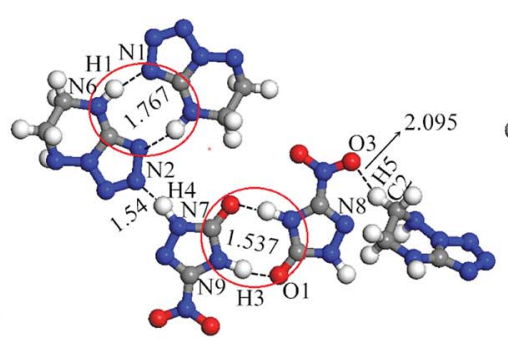

$4 \mathrm{GPa}$

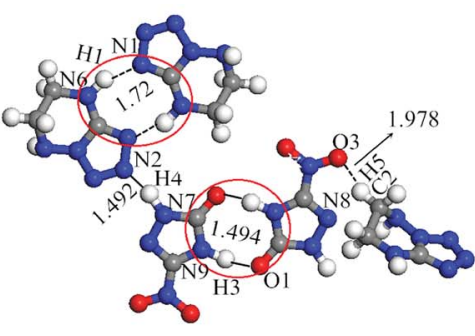

$8 \mathrm{GPa}$

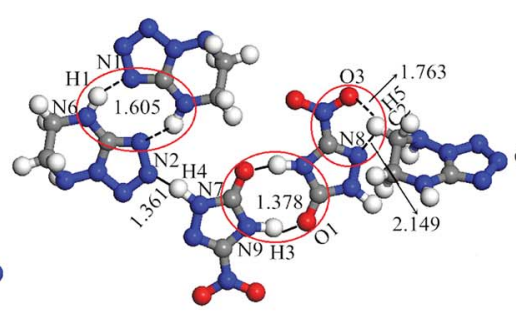

$30 \mathrm{GPa}$

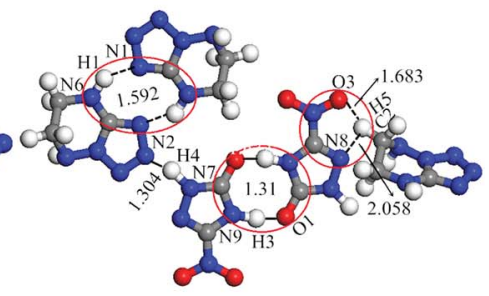

$50 \mathrm{GPa}$

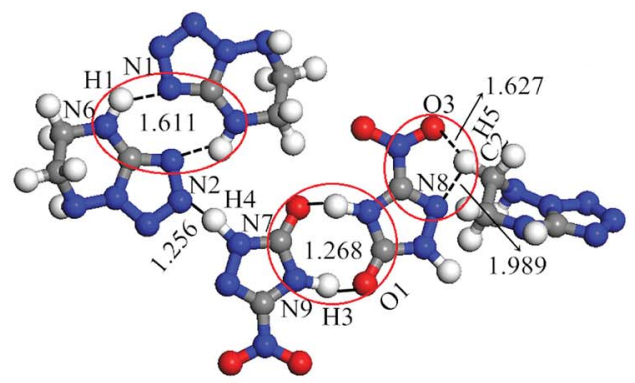

$70 \mathrm{GPa}$

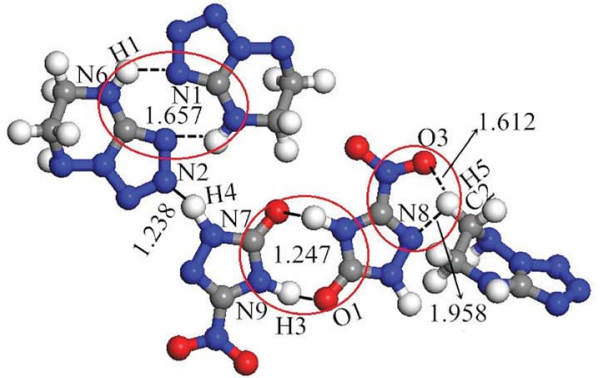

$80 \mathrm{GPa}$

Fig. 3 Perspective views on cocrystal NTO/TZTN with different pressures. 
during external compression, which is displayed in Fig. 3. The formation of five and eight membered rings have been observed for cocrystal NTO/TZTN under hydrostatic pressure. A new hydrogen bond forms between $\mathrm{H}$ and $\mathrm{O}(\mathrm{N})$ if the smallest and biggest distance are $1.5 \AA$ and $2.2 \AA$, respectively. ${ }^{50}$ To study the $\mathrm{H}$-bond in detail, bond lengths and interatomic distance of $\mathrm{N} 8 \cdots \mathrm{H} 5, \mathrm{O} 3 \cdots \mathrm{H} 5, \mathrm{~N} 2 \cdots \mathrm{H} 4, \mathrm{~N} 1 \cdots \mathrm{H} 1$, and $\mathrm{O} 1 \cdots \mathrm{H} 3$ are selected under different pressures described in Fig. 4. With the increasing of hydrostatic pressure from 0 to $80 \mathrm{GPa}$, the changes take place in the following two sections: the applied compression squeezes out the intermolecular space and causes the change of several hydrogen bonds in intramolecular geometry.

From Fig. 4, after $8 \mathrm{GPa}$, bond N6-H1 shorten gradually and the covalent interaction increases, which forms the eight

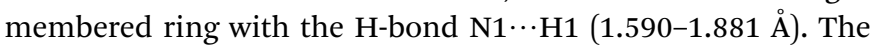
length of intermolecular $\mathrm{H}$-bond $\mathrm{O} 1 \cdots \mathrm{H} 3$ decreases obviously with increasing pressure. At $8 \mathrm{GPa}$, the $\mathrm{H}$-bond $\mathrm{O} 1 \cdots \mathrm{H} 3$ transforms into covalent bond (1.494 $\AA$ ), which forms the eight membered ring between two NTO molecules. In addition, as the pressure augments further to $8 \mathrm{GPa}$, the intermolecular $\mathrm{N} 2 \cdots \mathrm{H} 4$ contact $(1.492 \AA)$ has become more closer which leads to the transferring of hydrogen atom and formation of new covalent bond $\mathrm{N} 2-\mathrm{H} 4$. At $4 \mathrm{GPa}$, the hydrogen bond forms between $\mathrm{O} 3$ and $\mathrm{H} 5$ atoms (2.095 $\mathrm{\AA})$, and a large change in molecular structure has taken place. The interaction force of $\mathrm{H}$-bond $\mathrm{O} 3 \cdots$ $\mathrm{H} 5$ increase gradually with the pressure increasing to $80 \mathrm{GPa}$. When $23 \mathrm{GPa}$ is applied, the other new hydrogen bond forms between N8 and $\mathrm{H} 5$ atoms (2.196 ̊), and the five membered ring is built between NTO and TZTN, which leads to a larger conjugation system and makes cocrystal NTO/TZTN more stable as a whole. As the pressure increases, the formation of five and eight membered rings significantly improve the stability of cocrystal NTO/TZTN, which agree well with the resulted concluded from the structure determination. ${ }^{24}$

The calculations of crystal $\mathrm{NTO}^{51}$ and $\mathrm{TZTN}^{52}$ were carried out by DFT method at the same level in the pressure range of 0 $80 \mathrm{GPa}$. For crystal NTO and TZTN, from 0 to $80 \mathrm{GPa}$, the applied compression basically reduces the intermolecular voids. There is no large change in the bond length (all less than $1.5 \AA$ ), and transformation or fracture of chemical bond, which is different from the fact that three structural transformations occurred for cocrystal NTO/TZTN with the pressure of 4,8 , and $23 \mathrm{GPa}$.

3.2.2 QTAIM analysis. The QTAIM plays an important role in the course of study about the H-bond interactions in cocrystal NTO/TZTN, which described and demonstrated in Table 2 and Fig. 5, respectively. According to Table 2, two $\mathrm{H}$-bonds form between NTO and NTO, TZTN and TZTN, NTO and TZTN, except for $\mathrm{N} 7-\mathrm{H} 4 \cdots \mathrm{N} 2$. The reduction of distance in the $\mathrm{N}(\mathrm{O}) \cdots \mathrm{H}$ lead to the increase, in a steady way, of the absolute values of $\mathrm{H}$-bond energy $\left(E_{\mathrm{H}}\right)$. Furthermore, the absolute values of $\rho_{\mathrm{CP}}, \nabla^{2} \rho, V_{\mathrm{BCP}}$, and $G_{\mathrm{BCP}}$ keep increasing generally with the increase in the absolute values of $E_{\mathrm{H}}$, which suggests that these topological parameters are sensitive to the strength of $\mathrm{H}$-bonds. From 0 to $80 \mathrm{GPa}$, the negative $V_{\mathrm{BCP}}$ and positive $\nabla^{2} \rho$ always show the
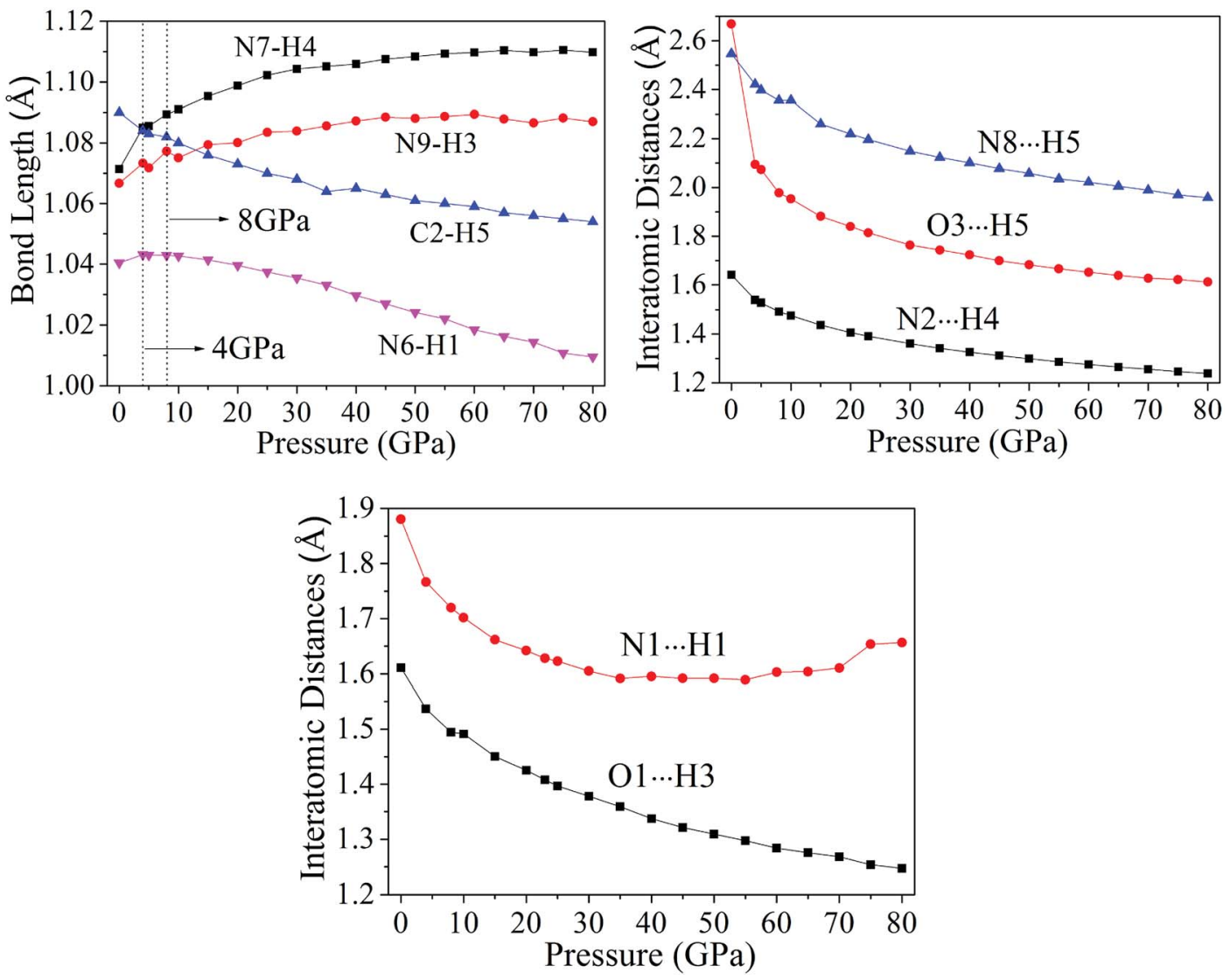

Fig. 4 Variation of the bond lengths and interatomic distances with pressures. 
Table 2 Selected QTAIM parameters [a.u.] and H-bond energy $E_{\mathrm{H}}\left[\mathrm{kJ} \mathrm{mol}{ }^{-1}\right]$ for the $\mathrm{H}$-bonds in cocrystal NTO/TZTN

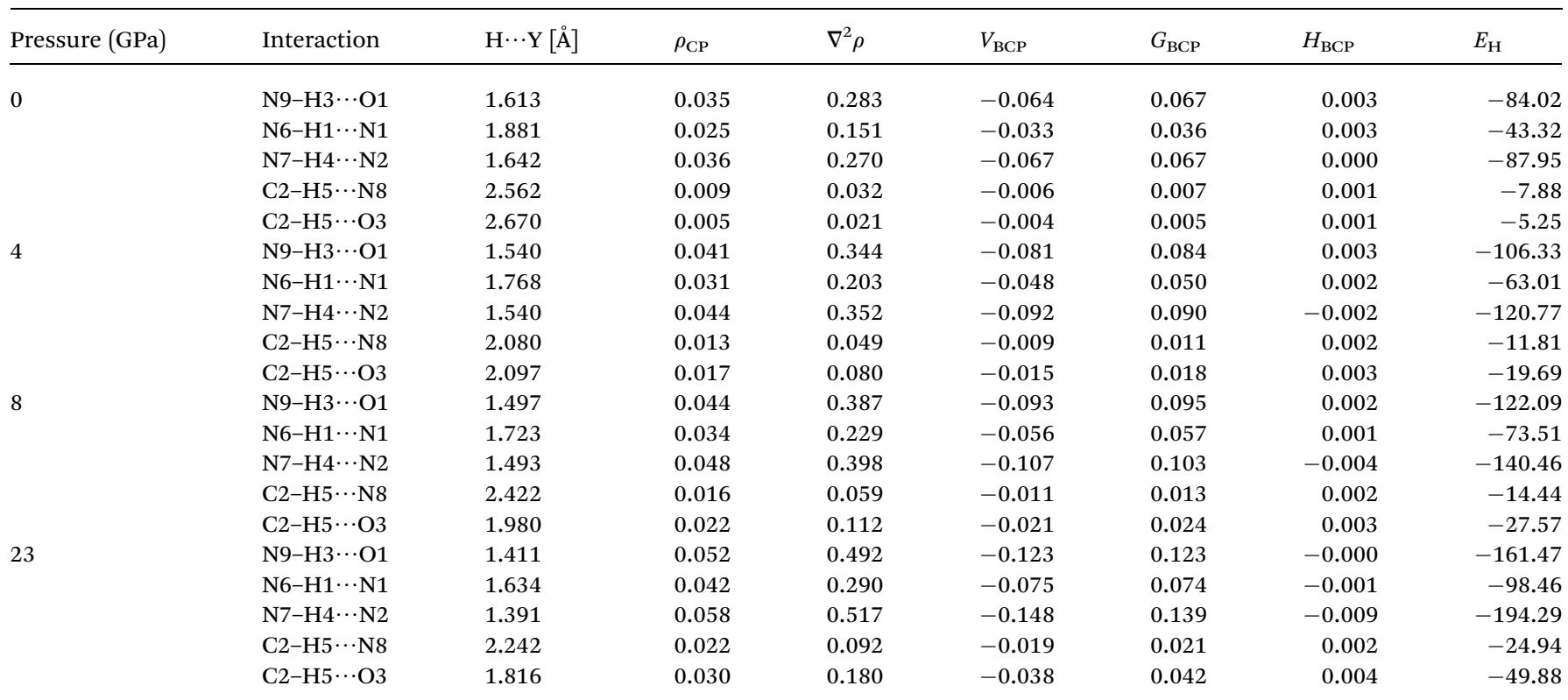

connection toward the covalency of interaction..$^{53}$ At $0 \mathrm{GPa}$, the electronic density at N8 $\cdots \mathrm{H} 5$ is 0.009 a.u., which is greater than that at $\mathrm{O} 3 \cdots \mathrm{H} 5(0.005$ a.u.). This is mainly because the shorter $\mathrm{N} 8 \cdots \mathrm{H} 5$ distance, which is comparable to the $\mathrm{O} 3 \cdots \mathrm{H} 5$ contacts observed in Table 2 . In addition, the H-bond energy of N8 $\cdots \mathrm{H} 5$ are about $-7.88 \mathrm{~kJ} \mathrm{~mol}^{-1}$ larger than those of $\mathrm{O} 3 \cdots \mathrm{H} 5$ $\left(-5.25 \mathrm{~kJ} \mathrm{~mol}^{-1}\right)$. Therefore, the $\mathrm{N} 8 \cdots \mathrm{H} 5$ interaction is stronger than that of O3 $\cdots \mathrm{H} 5$. This is similar for the other pressures except 8 and $23 \mathrm{GPa}$. At 8 and $23 \mathrm{GPa}$, the distance of $\mathrm{N} 8 \cdots \mathrm{H} 5$ is larger than that of $\mathrm{O} 3 \cdots \mathrm{H} 5$. Thus, the formation of $\mathrm{O} 3 \cdots \mathrm{H} 5$ at $4 \mathrm{GPa}$ and $\mathrm{N} 8 \cdots \mathrm{H} 5$ at $23 \mathrm{GPa}$ in cocrystal NTO/TZTN are the medium strength H-bonds groups, on the basis of the classifications of Rozas et al. ${ }^{54}$ and can be regarded as covalent interaction partially. $\mathrm{O} 1 \cdots \mathrm{H} 3$ and $\mathrm{N} 4 \cdots \mathrm{H} 2$ at $8 \mathrm{GPa}$ belong to the strong strength $\mathrm{H}$-bonds groups, which can be treated as covalent interaction.
Fig. 6 displays the tendency about H-bond energies of coc-

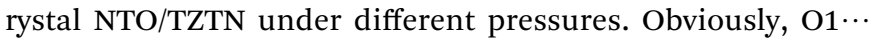
$\mathrm{H} 3, \mathrm{~N} 2 \cdots \mathrm{H} 4, \mathrm{~N} 8 \cdots \mathrm{H} 5, \mathrm{O} 3 \cdots \mathrm{H} 5$, and $\mathrm{N} 1 \cdots \mathrm{H} 1$ have the largest and smallest $\mathrm{H}$-bond energies at $80 \mathrm{GPa}$ and $0 \mathrm{GPa}$, respectively, which indicates that the structural voids is reduced by the applied compression in cocrystal NTO/TZTN and causes the increase of the $\mathrm{H}$-bond intermolecular interaction. To a certain degree, the applied compression contributes the improvement of cocrystal NTO/TZTN stability, which matches perfectly with the result from the analysis of bond length and interatomic distance. At the same pressure, $\mathrm{N} 2 \cdots \mathrm{H} 4$ has the biggest $\mathrm{H}$-bond energies and $\mathrm{N} 8 \cdots \mathrm{H} 5$ has the smallest. The stability increases in the order of $\mathrm{N} 8 \cdots \mathrm{H} 5<\mathrm{O} 3 \cdots \mathrm{H} 5<\mathrm{O} 1 \cdots \mathrm{H} 3$ $<\mathrm{N} 2 \cdots \mathrm{H} 4$, which signify that the formation of covalent interaction (O1 and $\mathrm{H} 3, \mathrm{~N} 4$ and $\mathrm{H} 2)$ at $8 \mathrm{GPa}$ increase thermal stability significantly.

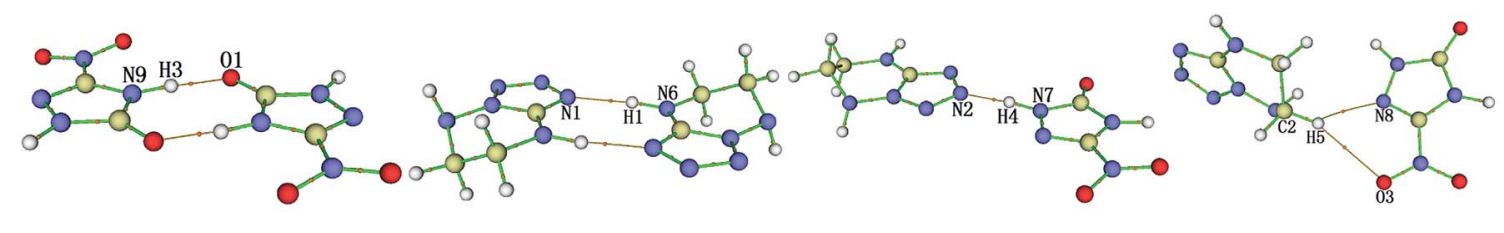

NTO-NTO $(0 \mathrm{GPa}) \quad$ TZTN-TZTN $(0 \mathrm{GPa}) \quad$ NTO-TZTN $(0 \mathrm{GPa}) \quad$ NTO-TZTN $(0 \mathrm{GPa})$

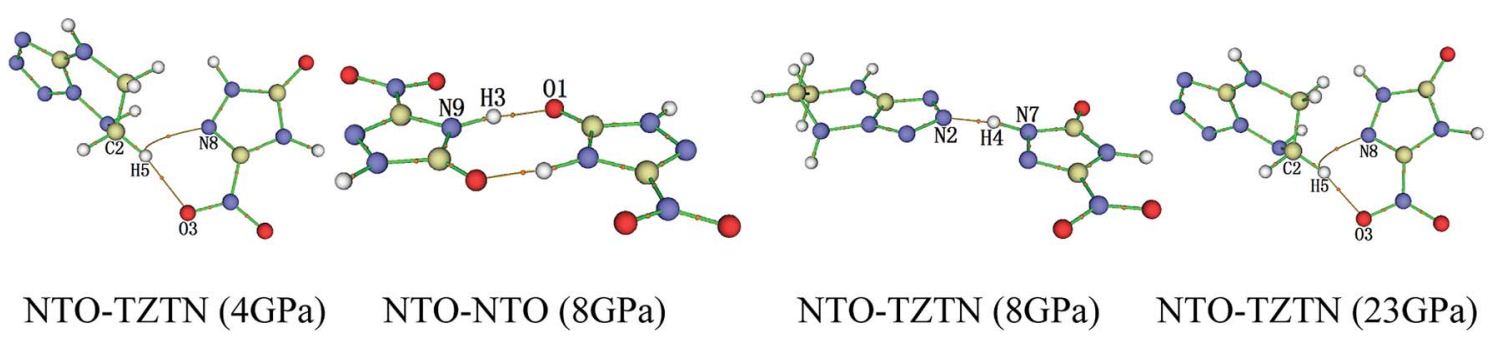

Fig. 5 The display of molecular structures and their corresponding $\mathrm{H}$-bond interactions at $0,4,8$, and $23 \mathrm{GPa}$. 


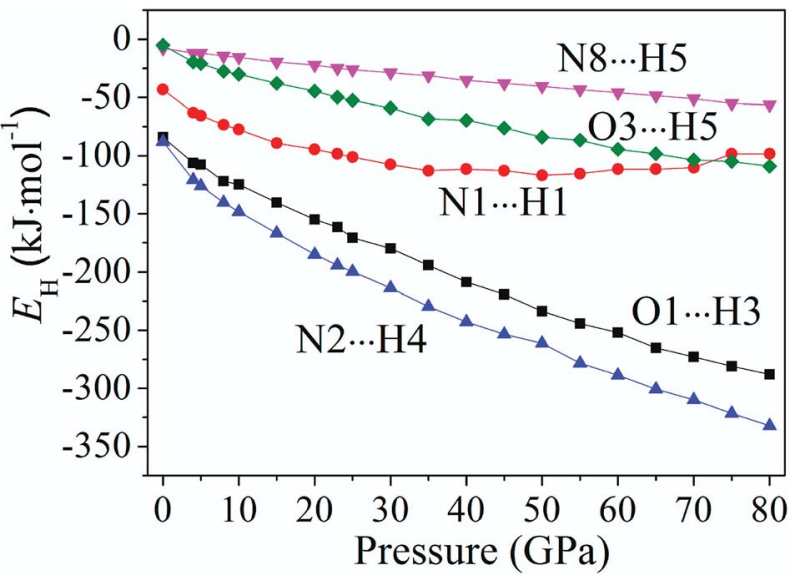

Fig. 6 The tendency of $\mathrm{H}$-bond energies with different pressures.

\subsection{Electronic structure}

The variation trends of several bonds' atomic charges and bond populations ${ }^{55-58}$ with pressure to cocrystal NTO/TZTN are depicted by Fig. 7. From 0 to $80 \mathrm{GPa}$, the positive charges on H1, $\mathrm{H} 3, \mathrm{H} 4$, and $\mathrm{H} 5$ decrease gradually, as same as the negative charges on N8, but increase on the negative charges of N6, N7, and N9. From 45 to $55 \mathrm{GPa}$, the atom charges, without significant change, tend to be more delocalized. With the formation of five membered rings at $23 \mathrm{GPa}$, the charge on $\mathrm{H} 5$ becomes less positive from 0.31 to $0.30 e$, and the charge on $\mathrm{C} 2$ becomes less negative from -0.34 to $-0.30 e$. The atom N8 obtains amount of charges considerably from -0.26 to $-0.28 e$. This means the transferring of the electron from $\mathrm{C} 2$ to N8. Due to the electron transfer, the bond $\mathrm{C} 2-\mathrm{H} 5$ becomes stronger because the bond order increases from 0.86 to 0.92 , and the bond N8 $\cdots \mathrm{H} 5$ turns to be weaker for the bond order decreases. As a result, the five membered rings in cocrystal NTO/TZTN are formed. Comparing with the formation of eight membered rings at $8 \mathrm{GPa}$, the atoms $\mathrm{N} 9$ and $\mathrm{O} 1$ lose a considerable amount of charges and become less negative from -0.51 to $-0.49 e$ and from -0.62 to $-0.60 e$, respectively. The charge of $\mathrm{H} 3$ is unchanged. This means that the electron is transferred from the atoms N9 and $\mathrm{O} 1$ to the triazole rings. Under the same pressure, it has the biggest and smallest $\mathrm{H}$-bond order for $\mathrm{N} 2 \cdots \mathrm{H} 4$ and $\mathrm{N} 8 \cdots \mathrm{H} 5$, respectively. The increase of stability, by the order, is $\mathrm{N} 8 \cdots \mathrm{H} 5<\mathrm{O} 3 \cdots \mathrm{H} 5<$ $\mathrm{O} 1 \cdots \mathrm{H} 3<\mathrm{N} 2 \cdots \mathrm{H} 4$, which agrees better with the result concluded from $\mathrm{H}$-bond energies.

According to the equilibrium crystal structures under different pressures, the calculation on the self-consistent band structures along different symmetry directions of the Brillouin zone ${ }^{59-61}$ has been pictured by Fig. 8. For the sake of a visualized view, there is merely a presentation of range from -1.0 to $4.0 \mathrm{eV}$. From 0 to $80 \mathrm{GPa}$, the energy bands between 1.0 and $2.0 \mathrm{eV}$ shift to the areas of lower energy. Below $4 \mathrm{GPa}$, the energy bands are flat and fluctuate little because cocrystal NTO/TZTN is a molecular crystal and the molecular interactions are weak. The energy bands become less flat across the Brillouin zone, and the bandwidth increases remarkably with the pressure increases from 4 to $80 \mathrm{GPa}$. This indicate that molecular interactions
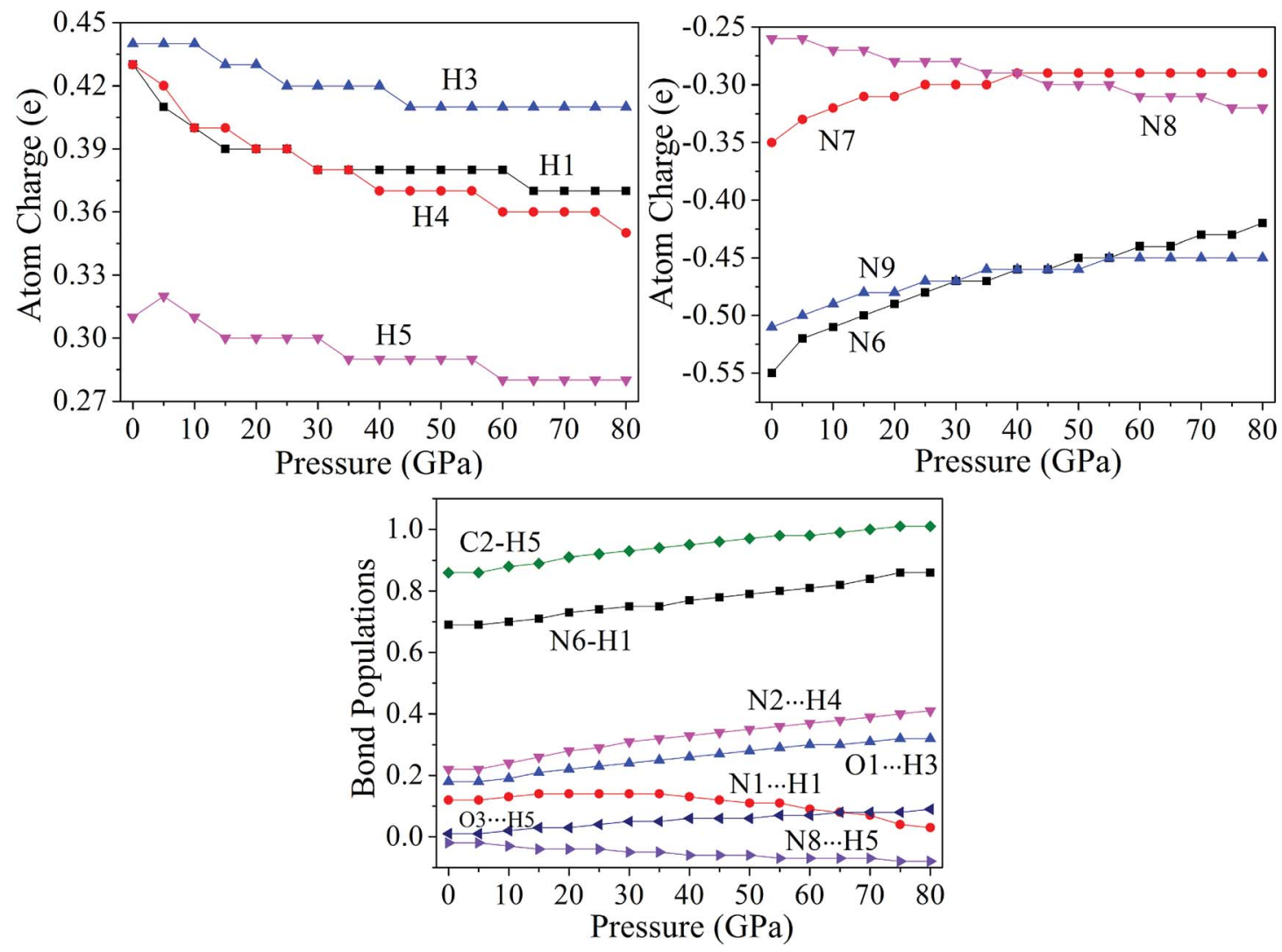

Fig. 7 Corresponding curves on atomic charges and bond populations of cocrystal NTO/TZTN under different pressures. 

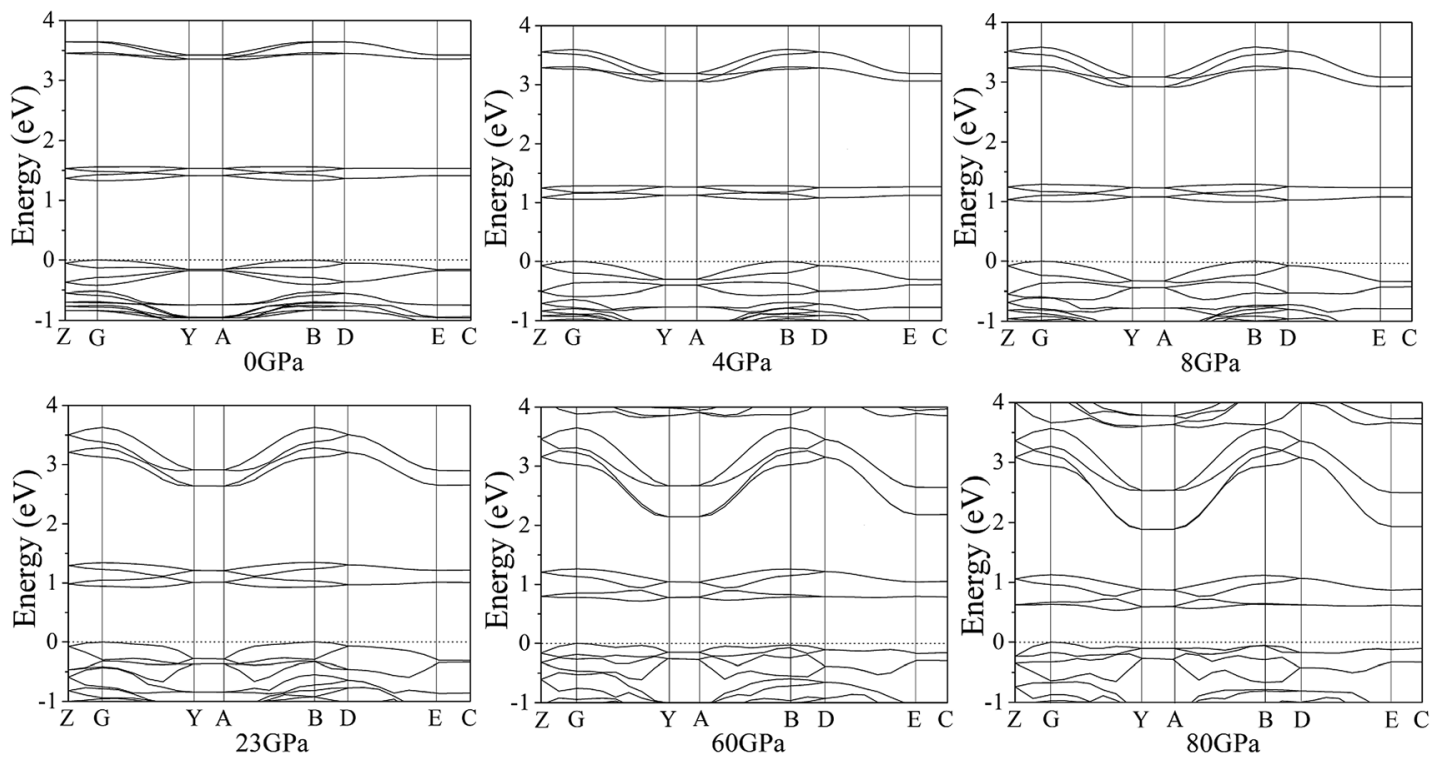

Fig. 8 Self-consistent band structures of cocrystal NTO/TZTN under different pressures. The Fermi energy is marked by a dashed horizontal line.

increase caused by the applied pressure. Important changes in the electronic properties can be obtained on the basis of the transformation in cocrystal NTO/TZTN at 8 and $23 \mathrm{GPa}$. As is shown, the energy bands get to a higher energy region, which means much wider on the conduction bands and much narrower on the valence bands than that in lower pressures.

Fig. 9 displays the band gaps of cocrystal NTO/TZTN under different pressures. With the pressure ranging from 0 to $80 \mathrm{GPa}$, illustrated by Fig. 9, the band gap shows continuous reduction. From 0 to $7 \mathrm{GPa}$, the decrease in band gaps causes the reduction of maximum energy in comparison with the high pressure region, which shows that a slight variation takes place in the electronic structure even though no evident change in molecular geometry. With the gradual increase of pressure from 0 to $7 \mathrm{GPa}$, the band gaps decrease suddenly and rapidly from 1.329 to $0.992 \mathrm{eV}$. Cocrystal NTO/TZTN transfers from the semiconductor to the metallic system under compression, which indicates that the electrons are more easily to transfer from occupied valence bands to empty conduction bands. From 8 to $35 \mathrm{GPa}$, the reduction of the band gap is in a slow way, because no obvious change occurred during the electron transitions from the occupied valence bands to the empty conduction bands. After $35 \mathrm{GPa}$, the band gap reduces significantly, which means that the electron is still more likely to transfer from occupied valence bands to empty conduction bands. The reduction tendency of band gap is related to the decrease in intermolecular space, which causes an increase of electron overlap between molecules in cocrystal NTO/TZTN under compression. To a certain extent, based on the principle of the easiest transition of electrons, ${ }^{62,63}$ with the pressure increasing, the decreasing gap reduces to the increasing sensitivity ${ }^{64,65}$

For a better understanding on the bond nature and electronic structure of cocrystal NTO/TZTN under different pressures, we conduct the investigation about the total density of states (DOS) and partial density of states (PDOS). ${ }^{66}$ The calculation of DOS for cocrystal NTO/TZTN under different pressures is illustrated by Fig. 10. According to Fig. 10, the curves of DOS have sharp peaks under low pressure, while the peaks become wider under higher pressure. The electrons demonstrate better mobility and moving freedom between the valence and conduction bands, hence, the cocrystal NTO/TZTN turns into metal under high pressure. That the conduction bands shift to the lower energy, not only reduces the band gap but also conclude a result that the probability of electronic excitations are augmented by crystal compression. Besides, electronic delocalization in cocrystal NTO/TZTN steadily increases. Because of some broadening effect in DOS curves, they are confined at the Fermi energy level. From $-10 \mathrm{eV}$ to the Fermi level, the $\mathrm{p}$ states are the dominating feature in the sharp peaks of valence and conduction band within the area of low or high pressure, which indicates $\mathrm{p}$ states play an irreplaceable role in terms of effect on the chemical reaction of cocrystal NTO/TZTN. At 4 and $8 \mathrm{GPa}$, it is noticeable that the DOS turns the double peaks into single peaks between -3.40 and $-2.00 \mathrm{eV}$ with the

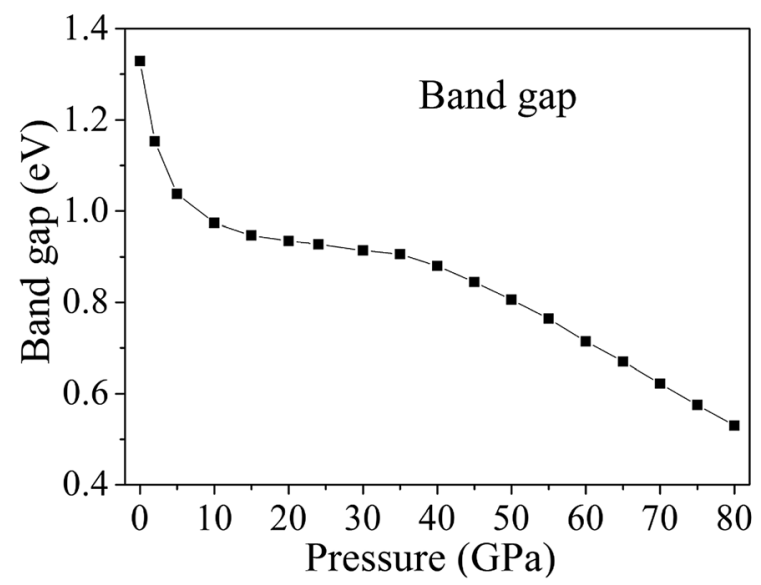

Fig. 9 The relationship between band gaps of cocrystal NTO/TZTN and pressures. 

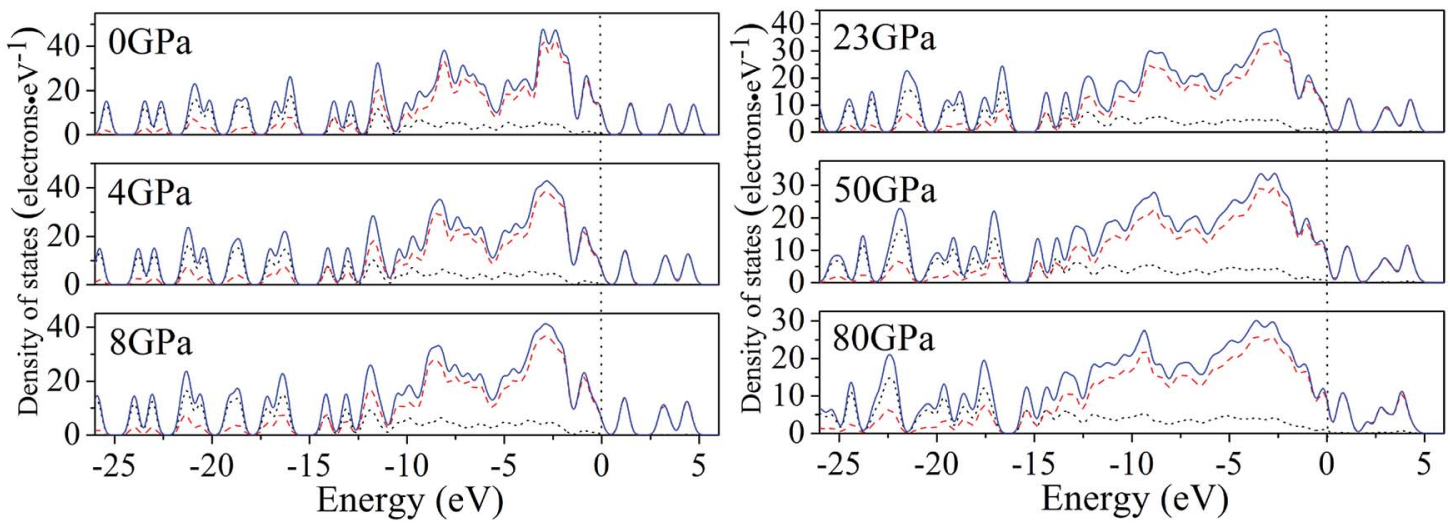

Fig. 10 Calculated total DOS for cocrystal NTO/TZTN under various pressures: s, p, and total states are marked by dotted, dashed, and solid curves, respectively.
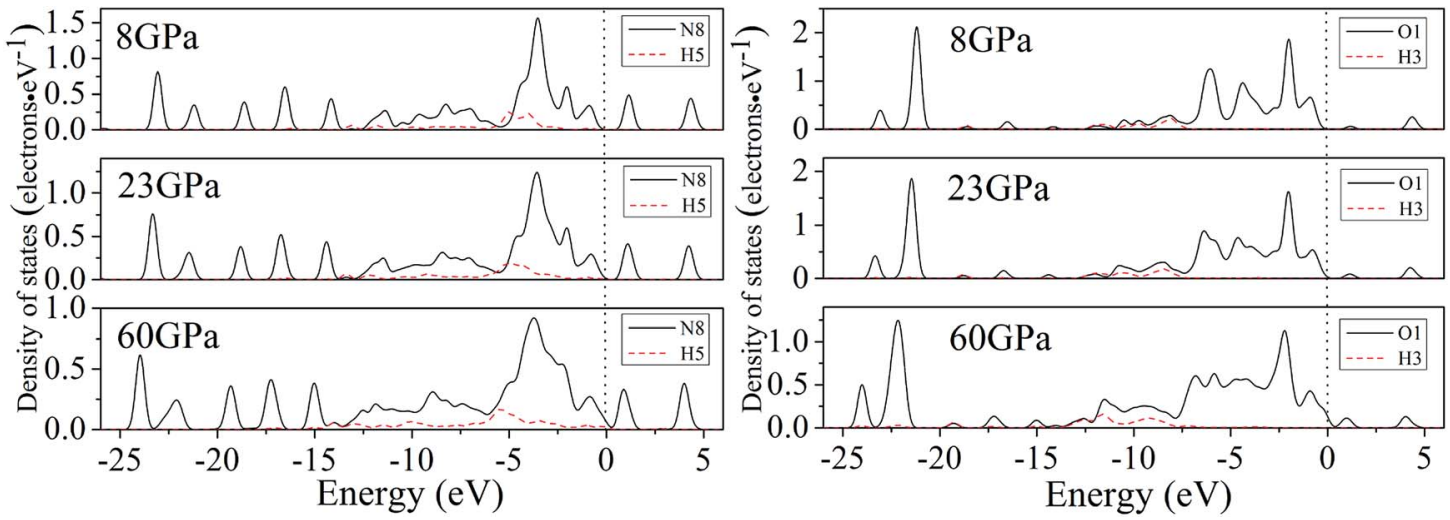

Fig. 11 The calculation of PDOS for N8, H5, O1 and $\mathrm{H} 3$ atoms under different pressures.

formation of $\mathrm{H}$-bond $\mathrm{O} 3 \cdots \mathrm{H} 5$ and covalent bond $\mathrm{O} 1-\mathrm{H} 3, \mathrm{~N} 2-$ $\mathrm{H} 4$, respectively. The formation of $\mathrm{H}$-bond $\mathrm{N} 8 \cdots \mathrm{H} 5$ caused that the DOS at $23 \mathrm{GPa}$ are quite different from that at $0 \mathrm{GPa}$, which matches well with the results concluded from molecular structure section. Fig. 11 describes the calculation of PDOS of the N8, $\mathrm{H} 5, \mathrm{O} 1$, and $\mathrm{H} 3$ atoms at 8,23 , and $60 \mathrm{GPa}$. Under different pressures, the existence of good interactions is obvious between $\mathrm{N} 8$ and $\mathrm{H} 5$ atoms, particularly in the energy range from -13.29 to $-0.92 \mathrm{eV}$, where the peaks tendency are in common with each other. At $8 \mathrm{GPa}$, a strong peak of the N8 atom appears at $-4.35 \mathrm{eV}$, while $\mathrm{H} 5$ atom shows the feature of weakness here. However, at $23 \mathrm{GPa}$, a strong peak appears at $-4.64 \mathrm{eV}$ for both $\mathrm{N} 8$ and $\mathrm{H} 5$ atoms. The main reason is that the $\mathrm{N} 8$ and $\mathrm{H} 5$ atoms are independent at $8 \mathrm{GPa}$ but form a H-bond $\mathrm{N} 8 \cdots \mathrm{H} 5$ at $23 \mathrm{GPa}$, which is in agreement with the analysis of molecular structure. Furthermore, at $8 \mathrm{GPa}$, the shape of the peaks are even very alike between $\mathrm{O} 1$ and $\mathrm{H} 3$ atoms from -12.27 to $-7.13 \mathrm{eV}$, which is attribute to the formation of covalent bond and the eight membered ring between two NTO molecules. Eventually, at 8 and $23 \mathrm{GPa}$, the upper valence bands and the lower conduction bands are predominated by the N, C states in skeleton rings, $\mathrm{O}$ states linked to the triazole rings and $\mathrm{N}$ states in nitro groups, respectively, which indicate that $\mathrm{C}$ and $\mathrm{N}$ atoms in skeleton rings, $\mathrm{O}$ atoms linked to the triazole rings, and $\mathrm{N}$ atoms in nitro groups act as the active center.

\section{Conclusions}

In this work, the effect of high pressure on the geometrical and electronic structures of cocrystal NTO/TZTN has been explored by the periodic first-principle calculations under hydrostatic pressure of 0-80 GPa. The GGA/PW91-OBS method has been employed in the present study. The optimized crystal structure by the GGA/PW91-OBS method at ambient pressure, matches better with the experimental constants in comparison with the other functionals. At 4,8 , and $23 \mathrm{GPa}$, molecular structure transforms due to the induced pressure. The stability of cocrystal system has been remarkably improved by the formation of five and eight membered rings during external compression. At $4 \mathrm{GPa}$, the hydrogen bond forms between $\mathrm{O} 3$ and $\mathrm{H} 5$ atoms, and the interaction force increases gradually with the pressure increasing to $80 \mathrm{GPa}$. At $8 \mathrm{GPa}$, the transformation from $\mathrm{H}$-bond $\mathrm{O} 1 \cdots \mathrm{H} 3$ to covalent bond contributes to the formation of the eight membered ring. Furthermore, a new covalent bond forms between $\mathrm{N} 2$ and $\mathrm{H} 4$ atoms. After $8 \mathrm{GPa}$, the covalent interaction of bond N6-H1 increases, which forms the eight membered ring with the $\mathrm{H}$-bond $\mathrm{N} 1 \cdots \mathrm{H} 1$ between two NTO molecules. When $23 \mathrm{GPa}$ is applied, the formation of $\mathrm{H}$-bond $\mathrm{N} 8 \cdots \mathrm{H} 5$ leads to the build of the five membered ring between NTO and TZTN. From the study of $\mathrm{H}$-bond energies, after $8 \mathrm{GPa}$, the covalent interaction between $\mathrm{O} 1$ and $\mathrm{H} 3$ atoms, $\mathrm{N} 4$ and $\mathrm{H} 2$ atoms, 
intensifies the thermal stability of cocrystal system significantly. With the growing increase of pressure, the energy bands show fluctuation across the Brillouin zone, while the bandwidth augments obviously. From 0 to $80 \mathrm{GPa}$, the reduction of band gap is connected with the decrease in intermolecular space, which makes the electron overlap increasing between molecules in cocrystal NTO/TZTN. The probability of electronic excitations are increased by the crystal compression, which has been proved by the analysis of density of states. The p state is the main character in the sharp peaks of valence and conduction band from $-10 \mathrm{eV}$ to the Fermi level. Basic information is provided by these results for the high pressure behavior of cocrystal NTO/TZTN.

\section{Conflicts of interest}

There are no conflicts to declare.

\section{Acknowledgements}

This work was supported by Scientific and Technological Innovation Programs of Higher Education Institutions in Shanxi (No. 2016157), and Natural Science Foundation of Shanxi Normal University Modern College of Humanities and Sciences (No. 2018JCYJ03). We are indebted to Associate Prof. Lei Zhang and Prof. Jun Chen for providing the crystal structure of the TZTN explosive.

\section{References}

1 Y. G. Xu, Q. Wang, C. Shen, Q. H. Lin, P. C. Wang and M. Lu, Nature, 2017, 549, 78.

2 W. Q. Zhang, J. H. Zhang, M. C. Deng, X. J. Qi, F. D. Nie and Q. H. Zhang, Nat. Commun., 2017, 8, 1.

3 K. B. Landenberger, O. Bolton and A. J. Matzger, J. Am. Chem. Soc., 2015, 137, 5074.

4 D. Fischer, J. L. Gottfried, T. M. Klapötke, K. Karaghiosoff, J. Stierstorfer and G. Witkowski, Angew. Chem., Int. Ed., 2016, 55, 16132.

5 H. Niu, S. S. Chen, Q. H. Shu, L. J. Li and S. H. Jin, J. Hazard. Mater., 2017, 338, 208.

6 S. Elbasuney, M. G. Zaky, M. Radwan and S. F. Mostafa, Appl. Surf. Sci., 2017, 419, 328.

7 T. M. Klapötke, B. Krumm and T. Reith, Eur. J. Org. Chem., 2017, 25, 3666.

8 D. Kumar, G. H. Imler, D. A. Parrish and J. M. Shreeve, Chem.-Eur. J., 2017, 23, 7876.

9 C. Deng, X. G. Xue, Y. Chi, H. Z. Li, X. P. Long and C. Y. Zhang, J. Phys. Chem. C, 2017, 121, 12101.

10 Z. B. Zhang, C. X. Xu, X. Yin and J. G. Zhang, Dalton Trans., 2017, 45, 19045.

11 J. C. Bennion, Z. R. Siddiqi and A. J. Matzger, Chem. Commun., 2017, 53, 6065.

12 S. R. Anderson, P. Dube, M. Krawiec, J. S. Salan, D. J. A. Ende and P. Samuels, Propellants, Explos., Pyrotech., 2016, 41, 783.

13 H. F. Gao, S. H. Zhang, F. D. Ren, F. Liu, R. J. Gou and X. Ding, Comput. Mater. Sci., 2015, 107, 33.
14 D. Z. Guo, Q. An, S. V. Zybin, W. A. Goddard, F. L. Huang and B. Tang, J. Mater. Chem. A, 2015, 3, 5409.

15 K. B. Landenberger and A. J. Matzger, Cryst. Growth Des., 2012, 12, 3603.

16 J. P. Shen, X. H. Duan, Q. P. Luo, Y. Zhou, Q. L. Bao, Y. J. Ma and C. H. Pei, Cryst. Growth Des., 2011, 11, 1759.

17 Z. W. Yang, H. Z. Li, X. Q. Zhou, C. Y. Zhang, H. Huang, J. S. Li and F. D. Nie, Cryst. Growth Des., 2012, 12, 5155.

18 O. Bolton and A. J. Matzger, Angew. Chem., Int. Ed., 2011, 50, 8960.

19 D. I. A. Millar, H. E. Maynard-Casely, D. R. Allan, A. S. Cumming, A. R. Lennie, A. J. Mackay, I. D. H. Oswald, C. C. Tang and C. R. Pulham, CrystEngComm, 2012, 14, 3742.

20 O. Bolton, L. R. Simke, P. F. Pagoria and A. J. Matzger, Cryst. Growth Des., 2012, 12, 4311.

21 V. W. Manchot and R. Noll, Justus Liebigs Ann. Chem., 1905, 343, 1 .

22 M. Zhang, C. Li, H. Q. Gao, W. Fu, Y. Y. Li, L. W. Tang and Z. M. Zhou, J. Mater. Sci., 2016, 51, 10849.

23 A. Golius, L. Gorb, A. M. Scott, F. C. Hill and J. Leszczynski, Struct. Chem., 2015, 226, 1281.

24 J. T. Wu, J. G. Zhang, T. Li, Z. M. Li and T. L. Zhang, RSC Adv., 2015, 5, 28354.

25 L. Zhang, J. Z. Wu, S. L. Jiang, Y. Yua and J. Chen, Phys. Chem. Chem. Phys., 2016, 18, 26960.

26 P. Y. Chen, L. Zhang, S. G. Zhu and G. B. Cheng, Def. Technol., 2015, 11, 132.

27 G. Z. Zhao and X. L. Yan, Quim. Nova, 2017, 40, 1141.

28 G. Z. Zhao, J. F. Jia and H. S. Wu, J. Chem. Sci., 2016, 128, 1223.

29 Z. A. Dreger, A. I. Stash, Z. G. Yu, Y. S. Chen, Y. C. Tao and Y. M. Gupta, J. Phys. Chem. C, 2016, 120, 1218.

30 H. Gao, P. Du, X. Ke, J. Liu, G. Z. Hao, T. Chen and W. Jiang, Propellants, Explos., Pyrotech., 2017, 42, 889.

31 H. Lin, J. F. Chen, S. G. Zhu, H. Z. Li and Y. Huang, J. Energ. Mater., 2017, 35, 95.

32 K. Liu, G. Zhang, J. Y. Luan, Z. Q. Chen, P. F. Su and Y. J. Shu, J. Mol. Struct., 2016, 1110, 91.

33 Z. B. Zhang, T. Li, L. Yin, X. Yin and J. G. Zhang, RSC Adv., 2016, 6, 76075.

34 Q. Wu, H. Chen, G. L. Xiong, W. H. Zhu and H. M. Xiao, J. Phys. Chem. C, 2015, 119, 16500.

35 D. C. Sorescu and B. M. Rice, J. Phys. Chem. C, 2010, 114, 6735.

36 Q. M. Hu, S. Lu and R. Yang, Phys. Rev. B: Condens. Matter Mater. Phys., 2008, 78, 052102.

37 D. Vanderbilt, Phys. Rev. B: Condens. Matter Mater. Phys., 1990, 41, 7892.

38 S. J. Clark, M. D. Segall, C. J. Pickard, P. J. Hasnip, M. J. Probert, K. Refson and M. C. Payne, Z. Kristallogr.Cryst. Mater., 2005, 220, 567.

39 Materials Studio 6.0, Accelrys, 2012.

40 M. J. Frisch, G. W. Trucks, H. B. Schlegel, G. E. Scuseria, M. A. Robb, J. R. Cheeseman, G. Scalmani, V. Barone, B. Mennucci, G. A. Petersson, H. Nakatsuji, M. Caricato, X. Li, H. P. Hratchian, A. F. Izmaylov, J. Bloino, G. Zheng, J. L. Sonnenberg, M. Hada, M. Ehara, K. Toyota, 
R. Fukuda, J. Hasegawa, M. Ishida, T. Nakajima, Y. Honda, O. Kitao, H. Nakai, T. Vreven, J. A. Montgomery, J. E. Peralta, F. Ogliaro, M. Bearpark, J. J. Heyd, E. Brothers, K. N. Kudin, V. N. Staroverov, R. Kobayashi, J. Normand, K. Raghavachari, A. Rendell, J. C. Burant, S. S. Iyengar, J. Tomasi, M. Cossi, N. Rega, J. M. Millam, M. Klene, J. E. Knox, J. B. Cross, V. Bakken, C. Adamo, J. Jaramillo, R. Gomperts, R. E. Stratmann, O. Yazyev, A. J. Austin, R. Cammi, C. Pomelli, J. W. Ochterski, R. L. Martin, K. Morokuma, V. G. Zakrzewski, G. A. Voth, P. Salvador, J. J. Dannenberg, S. Dapprich, A. D. Daniels, O. Farkas, J. B. Foresman, J. V. Ortiz, J. Cioslowski and D. J. Fox, Gaussian 09, Revision A.02, Gaussian Inc, Wallingford CT, 2009.

41 T. Lu and F. Chen, J. Comput. Chem., 2012, 33, 580.

42 E. Espinosa, E. Molins and C. Lecomte, Chem. Phys. Lett., 1998, 285, 170.

43 J. P. Perdew, K. Burke and M. Ernzerhof, Phys. Rev. Lett., 1996, 77, 3865.

44 J. P. Perdew and Y. Wang, Phys. Rev. B: Condens. Matter Mater. Phys., 1992, 45, 13244.

45 Z. C. Liu, Q. Wu, W. H. Zhu and H. M. Xiao, $R S C A d v ., 2015$, $5,34216$.

46 Q. Wu, W. H. Zhu and H. M. Xiao, J. Phys. Chem. C, 2013, 117, 16830.

47 M. J. Kamlet and S. J. Jacobs, J. Chem. Phys., 1968, 48, 23.

48 M. H. Keshavarz, K. Esmailpour, M. Zamani and A. G. Roknabadi, Propellants, Explos., Pyrotech., 2015, 40, 886.

49 Q. Yu, Z. X. Wang, B. Wu, H. W. Yang, X. H. Ju, C. X. Lv and G. B. Cheng, J. Mater. Chem. A, 2015, 3, 8156.
50 G. A. Jeffrey, An introduction to hydrogen bonding, Oxford University Press: New York, 1997.

51 N. B. Bolotina, K. Kirschbaum and A. A. Pinkerton, Acta Crystallogr., Sect. B: Struct. Sci., 2005, 61, 577.

52 L. Zhang and J. Chen, personal communication.

53 D. E. Hibbs, J. Overgaard and R. O. Piltz, Org. Biomol. Chem., 2003, 1, 1191.

54 I. Rozas, I. Alkorta and J. Elguero, J. Am. Chem. Soc., 2000, 122, 11154.

55 E. R. Davidson and S. Chakravorty, Theor. Chim. Acta, 1992, 83, 319.

56 M. D. Segall, C. J. Pickard, R. Shah and M. C. Payne, Mol. Phys., 1996, 89, 571.

57 M. D. Segall, R. Shah, C. J. Pickard and M. C. Payne, Phys. Rev. B, 1996, 54, 16317.

58 B. Winkler, C. J. Pickard, M. D. Segall and V. Milman, Phys. Rev. B: Condens. Matter Mater. Phys., 2001, 63, 214103.

59 P. Bag, M. E. Itkis, D. Stekovic, S. K. Pal, F. S. Tham and R. C. Haddon, J. Am. Chem. Soc., 2015, 137, 10000.

60 M. Konyk, L. Romaka, P. Demchenko, V. V. Romaka, Y. Stadnyk and A. Horyn, J. Alloys Compd., 2014, 589, 200.

61 P. V. Hatcher, J. H. Reibenspies, R. C. Haddon, D. W. Li, N. Lopez and X. L. Chi, CrystEngComm, 2015, 17, 4172.

62 J. J. Gilman, Philos. Mag. Lett., 1998, 77, 79.

63 S. V. Bondarchuk, Int. J. Quantum Chem., 2017, 117, e25430. $64 \mathrm{H}$. Zhang, F. Cheung, F. Zhao and X. L. Cheng, Int. J. Quantum Chem., 2009, 109, 1547.

65 W. H. Zhu and H. M. Xiao, Struct. Chem., 2010, 21, 657.

66 F. S. Saoud, J. C. Plenet and M. Henini, J. Alloys Compd., 2015, 619, 812 . 